and the methods of doing it. The set of resolutions adopted by the Conference, and printed in English and French, presents a mass of very detailed and valuable recommendations for future research. Although the Conference was concerned only with the locust problem in Africa and western Asia, the resolutions should be of great assistance in all countries where the locust problem is studied, because many of the recommendations with regard to the organisation and methods of research are applicable to any country. In view of the recent disastrous developments in the locust situation in South and North America, Australia and China, the work of the London Conference will undoubtedly have a worldwide appeal. It has laid a firm foundation for the international scientific attack on the locust problem and the main task of the next Conference, to be held in 1936 in Cairo, will be to extend the existing anti-locust front to all the countries suffering from these pests.

\section{Imperial Agricultural Research}

THE fourth annual report of the Executive Council of the Imperial Agricultural Bureaux, recently issued, continues the story of the smooth and successful working of an Imperially controlled and financed organisation (Imperial Agricultural Bureaux. Fourth Annual Report of the Executive Council, 1932-1933. Pp. 23. (London : H.M. Stationery Office, 1934.) 1s. net). The period under review marks the end of the two years' term of office of Mr. F. L. McDougall, the representative of Australia, as chairman of the Council ; and for the next two years Sir Charles $J$. Howell Thomas, the United Kingdom representative, has been elected chairman, with Mr. Nevill L. Wright, New Zealand, as vice-chairman. The most important event in the year was the inquiry made into the work and organisation of the Bureaux, in common with that of other inter-Imperial organisations, by the Imperial Committee on Economic Consultation and Co-operation, appointed as a result of one of the resolutions of the Ottawa Conference. That committee of inquiry not only recommended the continuance of the work but also accepted the organisation as a general model for inter-Imperial organisations and proposed that additional duties be placed on the Council. The main functions of the Bureaux are the collecting, sifting and distributing of information on research in eight branches of agricultural science; and the nine abstract journals already started have now become well established. In addition, a number of reviews with bibliographies on special subjects have been published, and the issue from Weybridge of the "Index Veterinarius"-a compete index of all papers and publications on veterinary science-has been sanctioned.

\section{Physical Investigation of 'Immaterial' Bodies}

THERE has recently been published by the Dr. William Bernard Johnston Foundation for Psychological Research, Reno, Nevada, a pamphlet by R. A. Watters entitled "The Intra-Atomic Quantity". Mr. Watters describes a series of experiments in which grasshoppers, frogs and mice were killed in a Wilson expansion chamber, a cloud produced at the moment of death, and the resulting 'tracks' photographed. It is alleged that these photographs reveal forms corresponding in shape to the dead bodies, and it is claimed that this result demonstrates the existence of an "intra-atomic Quantity" which is an "immaterial body" and an "exact counterpart of the physical body to which it belongs". It is further claimed that when the subjects of the experiments were removed from the Wilson chamber and gave any signs of life, the photographs never showed. anything unexpected; but that when the photographs showed 'intra-atomic' tracks, the subjects were unquestionably dead. Unfortunately, the few photographs reproduced in the bulletin before us reveal the alleged markings only to the eye of faith; for the rest, the essential experimental details are almost wholly wanting. If Mr. Watters wishes his work to receive attention, he should publish a more adequate and a more fully illustrated report.

\section{Calculating Machine for Simultaneous Equations}

The calculating machine for the solution of differential equations constructed by Dr. V. Bush, of the Massachusetts Institute of Technology, has attracted a great deal of attention, and a similar machine is being built in Great Britain by Prof. D. R. Hartree of Manchester. Dr. Bush has now, in collaboration with Dr. J. B. Wilbur, constructed another machine, the purpose of which is to give the solution of a number of simultaneous algebraic equations of the first degree. A larger model, containing nearly 1,000 pulleys and more than 500 feet of steel tape, has been designed, but is not yet constructed. This will deal with ten variables connected by ten equations, and will be of great use in the solution of problems such as the determination of stresses in buildings and the adjustment of triangular networks in surveying, which, treated by ordinary methods, require long and tedious calculations.

\section{Toads Save Sugar Crop}

Biological control seldom extends to the importation of Amphibia, but great success has followed the establishment of the large toad Bufo marinus in Puerto Rico. From two lots of this species brought to Puerto Rico from Barbadoes and Jamaica, millions of descendants have sprung, and the food of this host has consisted largely of the May-beetle (Science Service, Washington, D.C.). The sugar crop, which is the staple product of the island, was threatened by great numbers of the 'white-grubs' of May. beetles, which swarmed everywhere in the soil, devouring the roots of the cane and of other plants as well, so that the planters were reduced to picking the grubs by hand. The introduction of the toad has reduced the May-beetles to scarcity, and the Porto Rican sugar crop has been freed from its worst enemy.

\section{The 200-inch Mirror}

According to a message from its New York correspondent which appeared in the Times of December 